\title{
Brief Report: Hispanic Patients' Trajectory of Cancer Symptom Burden, Depression, Anxiety, and Quality of Life
}

\author{
Eida M. Castro-Figueroa ${ }^{1, *}$, Normarie Torres-Blasco ${ }^{1}$, Milagros C. Rosal ${ }^{2}$, Julio C. Jiménez ${ }^{1}$, Wallesca \\ P. Castro-Rodríguez ${ }^{3}$, Marilis González-Lorenzo ${ }^{1}$, Héctor Vélez-Cortés ${ }^{1}$, Alia Toro-Bahamonde ${ }^{4}$, \\ Rosario Costas-Muñiz ${ }^{5}{ }^{(0}$, Guillermo N. Armaiz-Peña ${ }^{1}{ }^{10}$ and Heather Jim ${ }^{6}$
}

check for updates

Citation: Castro-Figueroa, E.M.;

Torres-Blasco, N.; Rosal, M.C.;

Jiménez, J.C.; Castro-Rodríguez, W.P.; González-Lorenzo, M.; Vélez-Cortés,

H.; Toro-Bahamonde, A.;

Costas-Muñiz, R.; Armaiz-Peña, G.N.;

et al. Brief Report: Hispanic Patients'

Trajectory of Cancer Symptom

Burden, Depression, Anxiety, and

Quality of Life. Nurs. Rep. 2021, 11,

475-483. https://doi.org/10.3390/

nursrep11020044

Academic Editor: Richard Gray

Received: 23 April 2021

Accepted: 31 May 2021

Published: 9 June 2021

Publisher's Note: MDPI stays neutral with regard to jurisdictional claims in published maps and institutional affiliations.

Copyright: (c) 2021 by the authors. Licensee MDPI, Basel, Switzerland. This article is an open access article distributed under the terms and conditions of the Creative Commons Attribution (CC BY) license (https:// creativecommons.org/licenses/by/ $4.0 /)$.
1 Ponce Health Sciences University-Ponce Research Institute, Ponce 00716, Puerto Rico; normarietorres@psm.edu (N.T.-B.); jcjimenez@psm.edu (J.C.J.); marilisgonzalez@stu.psm.edu (M.G.-L.); hvelez@psm.edu (H.V.-C.); garmaiz@psm.edu (G.N.A.-P.)

2 Population and Quantitative Health Sciences, School of Medicine, University of Massachusetts Medical School, Worcester, MA 01605, USA; Milagros.Rosal@umassmed.edu

3 Christiana Care Health Center-Helen F. Graham Care Center, Wilmington, DE 19899, USA; wallesca.p.castrorodriguez@coh.org

4 Merck Pharmaceutical, Oncology Department, Kenilworth, NJ 07033, USA; alia.m.toro.bahamonde@merck.com

5 Memorial Sloan Kettering Cancer Center, Department of Psychiatry and Behavioral Sciences, Puerto Rico, CA 00984, USA; costasmr@mskcc.org

6 Moffitt Cancer Center, Tampa, FL 33612, USA; Heather.Jim@moffitt.org

* Correspondence: ecastro@psm.edu

Abstract: AbstractBackground: Anxiety and depression symptoms are known to increase cancer symptom burden, yet little is known about the longitudinal integrations of these among Hispanic/Latinx patients. The goal of this study was to explore the trajectory and longitudinal interactions among anxiety and depression, cancer symptom burden, and health-related quality of life in Hispanic/Latinx cancer patients undergoing chemotherapy. Methods: Baseline behavioral assessments were performed before starting chemotherapy. Follow-up behavioral assessments were performed at 3, 6, and 9 months after starting chemotherapy. Descriptive statistics, chi-square tests, Fisher's exact tests, and Mann-Whitney tests explored associations among outcome variables. Adjusted multilevel mixed-effects linear regression models were also used to evaluate the association between HADS scores, follow-up visits, FACT-G scale, MDASI scale, and sociodemographic variables. Results: Increased cancer symptom burden was significantly related to changes in anxiety symptoms' scores (adjusted $\hat{\beta}=0.11$ [95\% CI: 0.02, 0.19]. Increased quality of life was significantly associated with decreased depression and anxiety symptoms (adjusted $\hat{\beta}=-0.33 ; 95 \% \mathrm{CI}:-0.47$, -0.18 , and 0.38 adjusted $\hat{\beta}=-0.38 ; 95 \% \mathrm{CI}:-0.55,-0.20$, respectively). Conclusions: Findings highlight the need to conduct periodic mental health screenings among cancer patients initiating cancer treatment.

Keywords: Cancer; Cancer Symptom Burden; Quality of Life; Depression; Anxiety; Hispanic/Latinx

\section{Introduction}

Anxiety and depression symptoms, cancer symptom burden, and health-related quality of life are common symptoms experienced by patients under cancer care [1-3], and there is a lack of effort within the scientific community to understand them among Hispanics/Latinos. For patients undergoing chemotherapy, depression symptoms are up to four times higher than the US general population [4]. Regarding Hispanic/Latino cancer patients living in the US, they are even more elevated [5,6]. A systematic review reported that Hispanic breast cancer patients were more likely to report poor mental, physical, and social quality of life [7], yet these are cross-sectional data. Anxiety, depression, and 
cancer symptom burden are known to predict cancer patients' quality of life among nonHispanic cancer patients $[8,9]$. Furthermore, cancer patients undergoing cancer care exhibit increased anxiety and depression symptoms at the time of diagnosis and initiation of their cancer treatment (Breen et al., 2009). Still, studies documenting this in Hispanics are very limited [10-12].

The aim and hypothesis of this study were conceptualized based on the Health-related Quality of Life conceptual model [13]. The aim was to explore the longitudinal relationship among anxiety and depression symptoms, cancer symptom burden, and health-related quality of life in Hispanic cancer patients. The team hypothesized that participants under active oncology treatment experiencing greater depressive and anxiety symptomatology will report higher levels of cancer symptom burden and lower health-related quality of life.

\section{Materials and Methods}

The study was approved by the Ponce Research Institute IRB committee (protocol \#141007-EC). Baseline assessments were performed a week before starting chemotherapy, and quarterly for up to 9 months. Participants received a 10 USD incentive for each assessment/time point.

\subsection{Participants}

Participant recruitment took place at a community oncology clinic located in an urban area of Puerto Rico. Participants were recruited by convenience during their follow-up oncology appointment. Considering that this was a pilot study, the team estimated the sample size on the availability of participants for recruitment during the proposed time frame. Participant eligibility: 21 years of age and over, confirmed cancer diagnosis and scheduled to receive the first course of chemotherapy within the next 2 weeks after baseline assessment. Participant exclusion: had received any other cancer therapy (e.g., radiotherapy, hormonal therapy) 5 years prior to the recruitment date; were experiencing a depressive mood at the time of screening; use of illicit drugs or alcohol use disorder; history of psychotic disorders. A total of 96 patients were screened and 52 met the inclusion criteria.

\subsection{Measures}

Patient socio-demographic and clinical data: socio-demographic information was collected using a self-reported measure. Socio-demographic variables included age, sex, monthly income, education level, marital status, employment status, medical insurance, as well as religious and spiritual practices. Clinical information was gathered through medical chart reviews and included tumor site, tumor stage, and type of treatment. Self-reported personal and family history of mental health disorders data were collected.

Anxiety and depression symptoms: symptoms of anxiety and depression were assessed using the Spanish version of the Hospital and Anxiety Depression Scale (HADS). This 14-item scale evaluates the frequency of experiencing anxiety and depression symptoms. The HADS total scale Cronbach alpha is $0.88,0.85$ for the anxiety sub-scale, and 0.83 for the depression sub-scale [14]. It includes somatic symptoms of anxiety and depression (headaches, fatigue, insomnia, anergia, etc.) that can be caused by side effects related to cancer and its treatment [15].

Disease- and treatment-related symptoms: physical symptoms were assessed using the MD Anderson Symptom Inventory (MDASI). The MDASI [16] is a 19-item scale that measures cancer symptom severity (Cronbach alpha $=0.91$ ) and its interference (Cronbach alpha $=0.85)$ with daily life activities. Symptoms at their worst over the past $24 \mathrm{~h}$ and interference with daily activities are rated by participants on a 0 to 10 Likert scale.

Health quality of life: health-related quality of life was evaluated with the Spanish version of the Functional Assessment of Cancer Therapy-General Version 4 (FACT-G) developed by Cella [17]. This is a 28 -item scale designed to rate physical, social/family, emotional, and functional well-being using a 5-point Likert scale. Test-retest correlation 
reliability coefficients were 0.92 for the total score, 0.88 for physical well-being, 0.84 for functional well-being, 0.82 for social well-being, and 0.82 for emotional well-being.

\subsection{Data Analysis}

Descriptive statistics were used to characterize participants in the study. The association between depressive symptoms and socio-demographic characteristics was calculated using chi-square tests, Fisher's exact tests, and Mann-Whitney tests, as appropriate. Additionally, adjusted multilevel mixed-effects linear regression models were used to classify the association between HADS scores for depression and anxiety, period of time receiving oncology treatment (follow-up visits), participants' quality of life (FACT-G scale), cancer symptoms burden (MDASI scale), age, sex, and marital status; all variables were included in the adjusted model. A total of 50 participants were included in the linear mixed models, which used the full data set despite missing values at some time points. Data were missing at random, hence the means obtained from these models could be considered unbiased estimates. P-values less than 0.05 were considered statistically significant. Stata v.14 [18] was used to analyze all the data.

\section{Results}

Figure 1 presents patients' recruitment retention data and the reasons for not meeting the inclusion criteria. The recruitment rate was $60.46 \%$, and the attrition rate was $56 \%$.

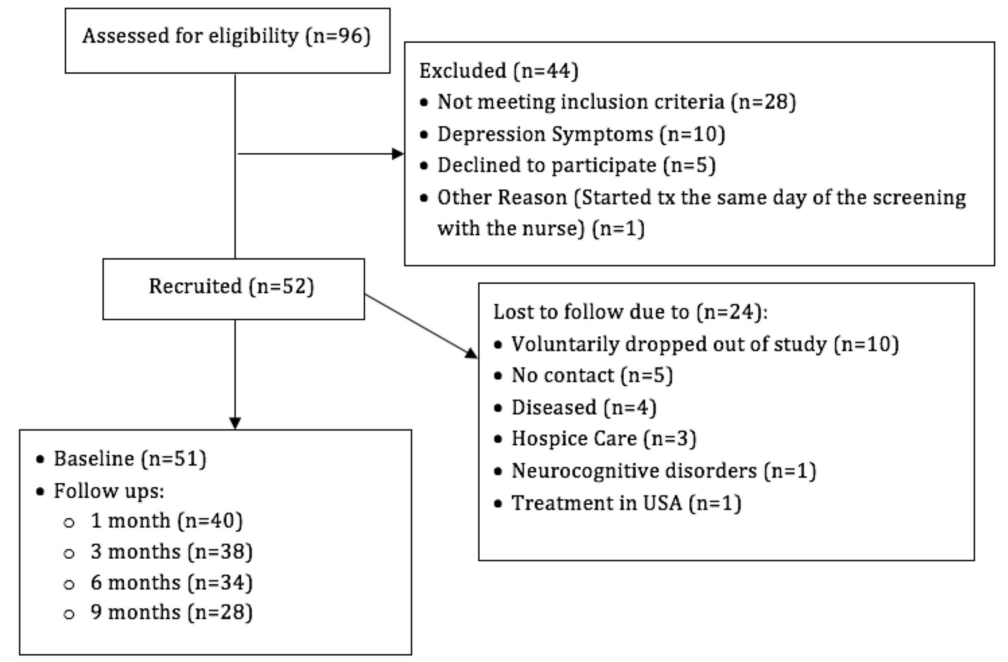

Figure 1. Presents patients' recruitment retention data and the reasons for not meeting the inclusion criteria. The recruitment rate was $60.46 \%$, and the attrition rate was $56 \%$. Screened patients $(n=10)$ and participants enrolled in the study $(n=5)$ who met clinical criteria for clinically significant depression/anxiety symptoms were referred to mental health services.

\subsection{Participants' Socio-Demographic and Clinical Characteristics}

More than half of this study's participants were males (58.8\%), had high school or greater education $(70.6 \%)$, and were married (62.8\%). Participants' mean age was 63.3 $( \pm 14.6)$ years. The distribution of other socio-demographic and clinical characteristics is shown in Table 1. The most common cancer types among participants included colon and rectum (19.6\%), breast (11.8\%), and pancreas (11.8\%); most of the malignancies were diagnosed in an advanced stage (44\%). About $39.3 \%$ (11 out of 28 who completed all study measures) of the participants exhibited clinically significant depressive symptoms at least once during the study period. No associations were found between the presence of depressive symptoms and socio-demographic characteristics $(p>0.05$; Table 2). 
Table 1. Socio-demographics and clinical features of participants $(n=51)$.

\begin{tabular}{|c|c|}
\hline Socio-Demographics & \\
\hline $\begin{array}{l}\text { Age } \\
\text { Mean } \pm \text { SD } \\
\quad \text { Median (min, max) }\end{array}$ & $\begin{array}{c}63.3 \pm 14.6 \\
66(23,86)\end{array}$ \\
\hline $\begin{array}{l}\text { Sex, } \mathbf{n}(\%) \\
\text { Male } \\
\text { Female }\end{array}$ & $\begin{array}{l}30(58.8) \\
21(41.2)\end{array}$ \\
\hline $\begin{array}{l}\text { Household composition, } \mathbf{n}(\%) \\
\text { Alone } \\
\text { Partner } \\
\text { Son/Daughter } \\
\text { Parents } \\
\text { Partner and Son/Daughter } \\
\text { Parents and Son/Daughter } \\
\text { Son/Daughter and Grandchildren } \\
\text { Partner, Son/Daughter, and Grandchildren } \\
\text { Other Family Members }\end{array}$ & $\begin{array}{c}8(15.7) \\
19(37.3) \\
5(9.8) \\
2(3.9) \\
10(19.6) \\
2(3.9) \\
2(3.9) \\
1(2.0) \\
2(3.9)\end{array}$ \\
\hline $\begin{array}{l}\text { Employment, } \mathbf{n}(\%) \\
\text { Employed } \\
\text { Unemployed } \\
\text { Disabled } \\
\text { Retired } \\
\text { Student } \\
\text { Other (did not specify) }\end{array}$ & $\begin{array}{c}6(11.8) \\
8(15.7) \\
4(7.8) \\
30(58.8) \\
1(2.0) \\
2(3.9)\end{array}$ \\
\hline $\begin{array}{c}\text { Education, } \mathbf{n}(\mathbf{\%}) \\
<\text { High School } \\
\geq \text { High School }\end{array}$ & $\begin{array}{l}15(29.4) \\
36(70.6) \\
\end{array}$ \\
\hline $\begin{array}{l}\text { Civil Status, n (\%) } \\
\text { Single } \\
\text { Married/Living with Partner } \\
\text { Divorced } \\
\text { Widowed }\end{array}$ & $\begin{array}{l}7(13.7) \\
32(62.8) \\
6(11.8) \\
6(11.8) \\
\end{array}$ \\
\hline $\begin{array}{l}\text { Medical Insurance }^{\dagger}, \mathbf{n}(\mathbf{\%}) \\
\text { Private } \\
\text { Health Care Reform } \\
\text { Medicare }\end{array}$ & $\begin{array}{l}14(28.0) \\
14(28.0) \\
22(44.0)\end{array}$ \\
\hline $\begin{array}{l}\text { Household Income, } \mathbf{n}(\%) \\
\leq \$ 19,000 \\
>\$ 19,000\end{array}$ & $\begin{array}{l}37(72.6) \\
14(27.4)\end{array}$ \\
\hline Clinical Features & \\
\hline $\begin{array}{l}\text { Tumour site (primary), n (\%) } \\
\text { Breast } \\
\text { Prostate } \\
\text { Multiple Myeloma } \\
\text { Head and Neck } \\
\text { Leukaemia } \\
\text { Lung } \\
\text { Pancreatic } \\
\text { Lymphoma } \\
\text { Colorectal } \\
\text { Stomach } \\
\text { Melanoma } \\
\text { Other sites } \ddagger \ddagger\end{array}$ & $\begin{array}{c}6(11.8) \\
5(9.8) \\
2(3.9) \\
3(5.9) \\
2(3.9) \\
3(5.9) \\
6(11.8) \\
5(9.8) \\
10(19.6) \\
2(3.9) \\
2(3.9) \\
5(9.8)\end{array}$ \\
\hline
\end{tabular}


Table 1. Cont.

\begin{tabular}{lc}
\hline Socio-Demographics & \\
\hline Disease stage, $\mathbf{n}(\mathbf{\%})$ & $6(12.0)$ \\
I ${ }^{++}$ & $9(18.0)$ \\
II & $13(26.0)$ \\
III & $22(44.0)$ \\
IV & \\
\hline
\end{tabular}

${ }^{\dagger}$ One missing value. ${ }^{\ddagger}$ Four participants had additional medical insurance; three with health care reform and one with Medicare. ${ }^{\S}$ Two participants also had Medicare. ${ }^{{ }^{\dagger+}}$ One patient also had a stage III multiple myeloma. 执 Includes Hodgkin, renal, urinary, gynaecological and mantel cell malignancies.

Table 2. Association between socio-demographic characteristics and presence of depressive symptoms $(\mathrm{n}=28)$.

\begin{tabular}{|c|c|c|c|}
\hline Characteristics & $\begin{array}{c}\text { Without } \\
\text { Depressive } \\
\text { Symptoms } \\
(\mathbf{n}=17)\end{array}$ & $\begin{array}{l}\text { With Depressive } \\
\text { Symptoms } \\
(\mathrm{n}=11)\end{array}$ & $p$-Value ${ }^{\dagger}$ \\
\hline Sex & & & $0.14 \ddagger$ \\
\hline Male & $11(64.7)$ & $4(36.4)$ & \\
\hline Female & $6(35.3)$ & 7 (63.6) & \\
\hline Age & & & 0.72 \\
\hline Mean $(+/-S D)$ & $59.2(14.9)$ & $62.4(15.5)$ & \\
\hline Median (P25-P75) & $65(55-67)$ & $63(47-78)$ & \\
\hline Household Income & & & 0.08 \\
\hline$\leq \$ 19,000$ & $15(88.2)$ & $6(54.6)$ & \\
\hline$>\$ 19,000$ & $2(11.8)$ & $5(45.5)$ & \\
\hline Income-Enough & & & $0.14 \ddagger$ \\
\hline No & $6(35.3)$ & $7(63.6)$ & \\
\hline Yes & $11(64.7)$ & $4(36.4)$ & \\
\hline Education & & & 0.65 \\
\hline$<$ High School & $3(17.7)$ & $3(27.3)$ & \\
\hline$\geq$ High School & $14(82.4)$ & $8(72.7)$ & \\
\hline Marital status & & & 0.08 \\
\hline Single & $4(23.5)$ & $0(0.0)$ & \\
\hline Married/Living with a partner & 9 (52.9) & $10(90.1)$ & \\
\hline Divorced & 3 (17.7) & $0(0.0)$ & \\
\hline Widowed & $1(5.9)$ & $1(9.1)$ & \\
\hline
\end{tabular}

Individuals who did not present depressive symptoms and did not complete all study visits were not included in the analysis due to possible misclassification as non-depressive symptoms. ${ }^{\dagger} p$-value was calculated using Fisher's Exact test and Mann-Whitney test when appropriate unless otherwise specified. $\ddagger p$-value was calculated using Chi-square test.

\subsection{Correlations among Anxiety, Depression, Cancer Symptom Burden, and Quality of Life}

Overall, a slight reduction in anxiety $(95 \% \mathrm{CI}:-0.28,0.18)$ and depression $(95 \% \mathrm{CI}$ : $-0.12,0.14)$ symptoms was observed through time among the participants, although not statistically significant. After adjusting for sex, age, marital status, quality of life, burden of cancer symptoms, and repeated measures effect among each participant, the overall HADS score mean during baseline measurements was 7.97 (95\% CI: 4.43, 11.51) for depression and 11.06 (95\% CI: 6.76, 15.36) for anxiety. The adjusted difference of the HADS score mean indicates that, between visits, participants had lower scores of depression symptoms during the first (1 month) and fourth (9 months) follow-up assessments as compared to baseline scores; changes in scores through time were not statistically significant. The HADS score for anxiety symptoms showed a significant decrease from 11.06 at baseline to 9.83 by the fourth visit (9 months) (adjusted $\hat{\beta}=-1.23,95 \% \mathrm{CI}:-2.27,-0.19$ ).

\subsection{Hypothesis Testing Multilevel Mixed-Effects Linear Regression Results}

Table 3 illustrates associations between quality of life, depression, and anxiety symptoms, accordingly. Each 5-unit increase in the FACT-G scale (i.e., better quality of life) was associated with significantly decreased HADS scores of depression and anxiety (adjusted 
$\hat{\beta}=-0.33 ; 95 \%$ CI: $-0.47,-0.18$ ) and 0.38 (adjusted $\hat{\beta}=-0.38 ; 95 \%$ CI: $-0.55,-0.20$ ), individually, once the team adjusted for confounders such as sex, age, and marital status. Meanwhile, another 5-unit increase in the burden of cancer symptoms showed significant changes in the HADS scores for anxiety (adjusted $\hat{\beta}=0.11$ [95\% CI: 0.02, 0.19]; Table 3). Sub-scales for symptom intensity and interference of symptoms with different aspects of the participants' life showed median values of 19 (Interquartile Range $[I Q R]=5,31$ ) and $6(\mathrm{IQR}=1.3,19.3)$, correspondingly. Furthermore, higher HADS scores of anxiety were observed among women as compared to men (adjusted $\hat{\beta}=1.91 ; 95 \%$ CI: $0.58,3.24$ ).

Table 3. Mixed linear regression models of HAD scale scores for depression and anxiety among individuals with cancer diagnosis receiving treatment $(n=51)$.

\begin{tabular}{|c|c|c|}
\hline Fixed Effect & $\begin{array}{c}\text { Depression Symptoms } \\
\text { Estimated } \beta(95 \% \mathrm{CI})\end{array}$ & $\begin{array}{c}\text { Anxiety Symptoms } \\
\text { Estimated } \beta(95 \% \mathrm{CI})\end{array}$ \\
\hline Intercept & $7.97(4.43,11.51)$ & $11.06(6.76,15.36)$ \\
\hline $\begin{array}{l}\text { Time point (visits) } \\
\text { Baseline } \\
1 \\
2 \\
3 \\
4\end{array}$ & $\begin{array}{c}\text { REFERENCE } \\
-0.23(-0.94,0.48) \\
0.19(-0.54,0.92) \\
-0.00(-0.75,0.75) \\
-0.39(-1.23,0.45)\end{array}$ & $\begin{array}{c}\text { REFERENCE } \\
-0.72(-1.60,0.16) \\
-0.19(-1.10,0.71) \\
-0.54(-1.47,0.39) \\
-1.23(-2.27,-0.19) \ddagger\end{array}$ \\
\hline $\begin{array}{l}\text { Sex } \\
\text { Male } \\
\text { Female }\end{array}$ & $\begin{array}{c}\text { REFERENCE } \\
0.85(-0.26,1.96)\end{array}$ & $\begin{array}{c}\text { REFERENCE } \\
1.91(0.58,3.24) \ddagger\end{array}$ \\
\hline Age $^{\dagger}$ & $-0.12(-0.33,0.10)$ & $-0.24(-0.50,0.02)$ \\
\hline $\begin{array}{l}\text { Marital Status } \\
\text { Single } \\
\text { Married/Living with Partner } \\
\text { Divorced } \\
\text { Widowed }\end{array}$ & $\begin{array}{c}\text { REFERENCE } \\
1.57(-0.24,3.38) \\
0.29(-1.95,2.54) \\
0.95(-1.74,3.65)\end{array}$ & $\begin{array}{c}\text { REFERENCE } \\
1.00(-1.15,3.16) \\
-0.37(-3.05,2.31) \\
1.80(-1.43,5.03)\end{array}$ \\
\hline Quality of Life $^{+}$ & $-0.33(-0.47,-0.18) \ddagger$ & $-0.38(-0.55,-0.20) \ddagger$ \\
\hline Burden of Cancer Symptoms ${ }^{\dagger}$ & $0.04(-0.03,0.11)$ & $0.11(0.02,0.19) \ddagger$ \\
\hline
\end{tabular}

${ }^{\dagger}$ Results are based on five units increase in the variable. ${ }^{\ddagger} p$-value $<0.05$.

Random effects for depression (LR test vs. linear model $=34.06 ; p<0.0001$ ) and anxiety (LR test vs. linear model $=21.72 ; p<0.0001$ ) showed that, for any visit, each participant might have a distinct intercept HADS scores up to 3.22 (depression) and 3.79 (anxiety) higher or lower than the average obtained from all participants as a group about $95 \%$ of the time. The variability of individual HADS scores during visits is around 1.60 and 2.00 for depression and anxiety, respectively, around the individual regression lines for each participant. Approximately $50.4 \%$ and $47.6 \%$ of the variance in HADS scores for depression and anxiety, respectively, can be attributed to differences between participants.

\section{Discussion}

At baseline, HADS scores were higher for anxiety symptoms than depression and, although anxiety symptoms decreased over time, these remained clinically significant. Rates of anxiety and depression after cancer diagnosis and before initiating oncology treatment may differ by type of cancer [19-21]. For instance, some studies report higher depression symptoms after cancer diagnosis and around the time of starting oncology treatment [22,23]. Symptoms of anxiety and depression diminished over time, with changes in depression symptoms being marginally significant. A study of colorectal cancer patients found that depression symptoms changed over time, where a longer time since diagnosis was associated with fewer depressive symptoms [24]. Even so, no significant changes over time in anxiety symptoms were found [24]. Another study revealed that clinical symptoms of anxiety and depression were prevalent at the completion of chemotherapy and, after completion of chemotherapy, depression symptoms decreased, and anxiety symptoms increased [25]. Another study found that symptoms of depression increased 
from pre-surgery up to 6 months, and symptoms of anxiety remained stable [26]. Similar to our results, Vahdaninia and colleagues found that anxiety and depression symptoms also improved over time [27].

Finally, as expected, the pilot cohort study found significant associations among anxiety, depression, and quality of life. Yet, no significant associations were found between changes in anxiety and depression and cancer symptom severity throughout 9 months. One potential explanation for the differences in the findings and results from other research groups could be that the team excluded patients that reported depression symptoms at the time of recruitment (exclusion criteria \#2). The team excluded these patients because they wanted to observe the course of depression symptoms that emerged after cancer treatment. Thus, the interpretation of these results may apply exclusively to cancer patients who do not present clinically significant depression symptoms at the time of cancer treatment initiation. Of note, other studies have yielded significant associations among symptoms of depression, anxiety, and cancer symptom burden. For instance, a study conducted by Shi and collaborators revealed that, among cancer patients reporting high cancer symptom burden, depression (along with fatigue and pain) had the most significant impact on their quality of life [28]. Two cross-sectional studies among patients with advanced-staged cancer found significant correlations between depression severity, number of reported physical symptoms, and symptom severity independent of cancer type [29,30]. Another study among breast cancer patients that utilized the Distress Thermometer's Physical Problem List revealed that most physical problems were associated with depression (87\% of symptoms) and anxiety (53\% of symptoms) [31]. Likewise, Leonhart and colleagues found that, among other factors, anxiety and depression symptoms predicted higher somatic symptom severity $[32,33]$.

\section{Conclusions}

This pilot study suggests cancer patients experience higher symptoms of anxiety at chemotherapy treatment initiation. Moreover, even though anxiety symptoms decreased over time, such symptoms remained high. These findings highlight the need to conduct periodic mental health screenings among cancer patients initiating cancer treatment. This study will inform a large-sample observational longitudinal study aimed at developing a comprehensive model predicting the longitudinal mediation and moderator interactions among anxiety and depression symptoms, cancer symptom burden, and health-related quality of life. Such study is needed to inform effective mental health screening efforts and interventions targeting Hispanic cancer patients under active oncology treatment.

Author Contributions: Study conception and design: E.M.C.-F., M.C.R., J.C.J., and H.J. Acquisition of data: N.T.-B, M.G.-L., W.P.C.-R., H.V.-C., and A.T.-B. Analysis and interpretation of data: E.M.C.F., N.T.-B., and R.C.-M. Drafting of manuscript: E.M.C.-F., M.C.R., M.G.-L., N.T.-B., and G.N.A.-P. Critical revision: A.T.-B. and H.J., G.N.A.-P. All authors have read and agreed to the published version of the manuscript.

Funding: This research was funded by the United States' National Institute of Minority Health and Health Disparities (5R25MD007607). Eida M. Castro-Figueroa received support from the National Cancer Institute (2U54CA163071 and 2U54CA163068) and the National Institute of Minority Health and Health Disparities (5G12MD007579-33, U54MD007579, 5R25MD007607, and R21MD013674). Normarie Torres received grant support from the American Cancer Society (133798-PF-19-120-01CPPB). Milagros C. Rosal received grant support from the National Institute of Minority Health and Health Disparities (5 P60 MD006912) and the Centers for Disease Control and Prevention (1U48DP005031). Rosario Costas-Muñiz received grant support from the National Cancer Institute R21CA180831-02 (Cultural Adaptation of Meaning-Centered Psychotherapy for Latinos), and the Memorial Sloan Kettering Cancer Center grant (P30CA008748). The funders had no role in study design, data collection, and analysis, decision to publish, or preparation of the manuscript. The content is solely the responsibility of the authors and does not necessarily represent the official views of the funding organizations. 
Institutional Review Board Statement: The study was conducted according to the guidelines of the Declaration of Helsinki and approved by the Institutional Review Board of Ponce Health Sciences University-Ponce Research Institute (protocol code 141007-EC) approved on 25 January 2015.

Informed Consent Statement: Informed consent was obtained from participants involved in the study.

Data Availability Statement: The data presented in this study will be available in the supplementary material contained in this article.

Acknowledgments: The team would like to acknowledge the contribution of Lorena GonzálezSepúlveda from the Puerto Rico Clinical and Translational Research Consortium for her support with statistical analysis (U54MD007587 and U54GM133807). The content is solely the responsibility of the authors and does not necessarily represent the official views of the National Institutes of Health.

Conflicts of Interest: Heather Jim serves as a consultant to RedHill BioPharma and Janssen Scientific Affairs. Alia Bahamode is an employee of Merk-Puerto Rico. The other authors declare that they have no competing interests. The funders had no role in the design of the study; in the collection, analyses, or interpretation of data; in the writing of the manuscript, or in the decision to publish the results.

\section{References}

1. Mitchell, A.J.; Chan, M.; Bhatti, H.; Halton, M.; Grassi, L.; Johansen, C.; Meader, N. Prevalence of depression, anxiety, and adjustment disorder in oncological, haematological, and palliative-care settings: A meta-analysis of 94 interview-based studies. Lancet Oncol. 2011, 12, 160-174. [CrossRef]

2. Mitchell, A.J.; Ferguson, D.W.; Gill, J.; Paul, J.; Symonds, P. Depression and anxiety in long-term cancer survivors compared with spouses and healthy controls: A systematic review and meta-analysis. Lancet Oncol. 2013, 14, 721-732. [CrossRef]

3. Jacob, L.; Kalder, M.; Kostev, K. Incidence of depression and anxiety among women newly diagnosed with breast or genital organ cancer in Germany. Psycho-Oncol. 2017, 26, 1535-1540. [CrossRef] [PubMed]

4. Snyderman, D.; Wynn, D. Depression in cancer patients. Prim. Care 2009, 36, 703-719. [CrossRef]

5. Luckett, T.; Goldstein, D.; Butow, P.N.; Gebski, V.; Aldridge, L.J.; McGrane, J.; Ng, W.; King, M.T. Psychological morbidity and quality of life of ethnic minority patients with cancer: A systematic review and meta-analysis. Lancet Oncol. 2011, 12, 1240-1248. [CrossRef]

6. Costas, R.; Gany, F. Depressive symptoms in a sample of Afro-Caribbean and Latino immigrant cancer patients: A comparative analysis. Supportive Care Cancer 2013, 21, 2461-2468. [CrossRef] [PubMed]

7. Yanez, B.; Thompson, E.H.; Stanton, A.L. Quality of life among Latina breast cancer patients: A systematic review of the literature. J. Cancer Surviv. 2011, 5, 191-207. [CrossRef] [PubMed]

8. Gold, M.; Dunn, L.B.; Phoenix, B.; Paul, S.M.; Hamolsky, D.; Levine, J.D.; Miaskowski, C. Co-occurrence of anxiety and depressive symptoms following breast cancer surgery and its impact on quality of life. Eur. J. Oncol. Nurs. 2016, 20, 97-105. [CrossRef]

9. Hulbert-Williams, N.; Neal, R.; Morrison, V.; Hood, K.; Wilkinson, C. Anxiety, depression and quality of life after cancer diagnosis: What psychosocial variables best predict how patients adjust? Psycho Oncol. 2012, 21, 857-867. [CrossRef]

10. Gonzalez-Mercado, V.J.; Saligan, L.N.; Ji, M.; Groer, M.; Pedro, E.; McMillan, S. Differences in the severity, distress, interference, and frequency on cancer-related symptoms between Island Hispanic Puerto Ricans and Mainland non-Hispanic Whites. J. Immigr. Minority Health 2018, 20, 1029-1039. [CrossRef]

11. Krok-Schoen, J.L.; Fernandez, K.; Unzeitig, G.W.; Rubio, G.; Paskett, E.D.; Post, D.M. Hispanic breast cancer patients' symptom experience and patient-physician communication during chemotherapy. Supportive Care Cancer 2019, 27, 697-704. [CrossRef]

12. Check, D.K.; Chawla, N.; Kwan, M.L.; Pinheiro, L.; Roh, J.M.; Ergas, I.J.; Stewart, A.L.; Kolevska, T.; Ambrosone, C.; Kushi, L.H. Understanding racial/ethnic differences in breast cancer-related physical well-being: The role of patient-provider interactions. Breast Cancer Res. Treat. 2018, 170, 593-603. [CrossRef]

13. Wilson, I.B.; Cleary, P.D. Linking clinical variables with health-related quality of life. A conceptual model of patient outcomes. JAMA 1995, 273, 59-65. [CrossRef]

14. Hyland, K.A.; Hoogland, A.I.; Gonzalez, B.D.; Nelson, A.M.; Lechner, S.; Tyson, D.M.; Barata, A.; Gomez, M.F.; Antoni, M.H.; Small, B.; et al. Evaluation of the Psychometric and Structural Properties of the Spanish Version of the Hospital Anxiety and Depression Scale in Latina Cancer Patients. J. Pain Symptom Manag. 2019. [CrossRef] [PubMed]

15. Bjelland, I.; Dahl, A.A.; Haug, T.T.; Neckelmann, D. The validity of the Hospital Anxiety and Depression Scale: An updated literature review. J. Psychosom. Res. 2002, 52, 69-77. [CrossRef]

16. Cleeland, C.S.; Mendoza, T.R.; Wang, X.S.; Chou, C.; Harle, M.T.; Morrissey, M.; Engstrom, M.C. Assessing symptom distress in cancer patients: The MD Anderson Symptom Inventory. Cancer Interdiscip. Int. J. Am. Cancer Soc. 2000, 89, 1634-1646. [CrossRef]

17. Cella, D.F.; Tulsky, D.S.; Gray, G.; Sarafian, B.; Linn, E.; Bonomi, A.; Silberman, M.; Yellen, S.B.; Winicour, P.; Brannon, J. The Functional Assessment of Cancer Therapy scale: Development and validation of the general measure. J. Clin. Oncol. Off. J. Am. Soc. Clin. Oncol. 1993, 11, 570-579. [CrossRef]

18. StataCorp. Stata Statistical Software: Release 14; StataCorp LP: College Station, TX, USA, 2015. 
19. Linden, W.; Vodermaier, A.; MacKenzie, R.; Greig, D. Anxiety and depression after cancer diagnosis: Prevalence rates by cancer type, gender, and age. J. Affect. Disord. 2012, 141, 343-351. [CrossRef]

20. Hess, C.B.; Chen, A.M. Measuring psychosocial functioning in the radiation oncology clinic: A systematic review. Psycho-Oncol. 2014, 23, 841-854. [CrossRef] [PubMed]

21. Lee, M.S.; Tyson, D.M.; Gonzalez, B.D.; Small, B.J.; Lechner, S.C.; Antoni, M.H.; Vinard, A.; Krause, M.; Meade, C.; Jacobsen, P.B. Anxiety and depression in S Spanish-speaking Latina cancer patients prior to starting chemotherapy. Psycho Oncol. 2018, 27, 333-338. [CrossRef]

22. Stafford, L.; Judd, F.; Gibson, P.; Komiti, A.; Mann, G.B.; Quinn, M. Anxiety and depression symptoms in the 2 years following diagnosis of breast or gynaecologic cancer: Prevalence, course and determinants of outcome. Supportive Care Cancer 2015, 23, 2215-2224. [CrossRef]

23. Chung, J.; Ju, G.; Yang, J.; Jeong, J.; Jeong, Y.; Choi, M.K.; Kwon, J.; Lee, K.H.; Kim, S.T.; Han, H.S. Prevalence of and factors associated with anxiety and depression in Korean patients with newly diagnosed advanced gastrointestinal cancer. Korean J. Intern. Med. 2018, 33, 585. [CrossRef]

24. Mols, F.; Schoormans, D.; de Hingh, I.; Oerlemans, S.; Husson, O. Symptoms of anxiety and depression among colorectal cancer survivors from the population-based, longitudinal PROFILES Registry: Prevalence, predictors, and impact on quality of life. Cancer 2018, 124, 2621-2628. [CrossRef]

25. Hipkins, J.; Whitworth, M.; Tarrier, N.; Jayson, G. Social support, anxiety and depression after chemotherapy for ovarian cancer: A prospective study. Br. J. Health Psychol. 2004, 9, 569-581. [CrossRef]

26. Hellstadius, Y.; Lagergren, J.; Zylstra, J.; Gossage, J.; Davies, A.; Hultman, C.M.; Lagergren, P.; Wikman, A. A longitudinal assessment of psychological distress after oesophageal cancer surgery. Acta Oncol. 2017, 56, 746-752. [CrossRef] [PubMed]

27. Vahdaninia, M.; Omidvari, S.; Montazeri, A. What do predict anxiety and depression in breast cancer patients? A follow-up study. Soc. Psychiatry Psychiatr. Epidemiol. 2010, 45, 355-361. [CrossRef] [PubMed]

28. Shi, Q.; Smith, T.G.; Michonski, J.D.; Stein, K.D.; Kaw, C.; Cleeland, C.S. Symptom burden in cancer survivors 1 year after diagnosis: A report from the American Cancer Society's Studies of Cancer Survivors. Cancer 2011, 117, 2779-2790. [CrossRef] [PubMed]

29. Grotmol, K.S.; Lie, H.C.; Loge, J.H.; Aass, N.; Haugen, D.F.; Stone, P.C.; Kaasa, S.; Hjermstad, M.J. Patients with advanced cancer and depression report a significantly higher symptom burden than non-depressed patients. Palliat. Support. Care 2019, 17, 143-149. [CrossRef] [PubMed]

30. Yennurajalingam, S.; Tayjasanant, S.; Balachandran, D.; Padhye, N.S.; Williams, J.L.; Liu, D.D.; Frisbee-Hume, S.; Bruera, E. Association between daytime activity, fatigue, sleep, anxiety, depression, and symptom burden in advanced cancer patients: A preliminary report. J. Palliat. Med. 2016, 19, 849-856. [CrossRef] [PubMed]

31. McFarland, D.C.; Shaffer, K.M.; Tiersten, A.; Holland, J. Physical symptom burden and its association with distress, anxiety, and depression in breast cancer. Psychosomatics 2018, 59, 464-471. [CrossRef]

32. Leonhart, R.; Tang, L.; Pang, Y.; Li, J.; Song, L.; Fischer, I.; Koch, M.; Wuensch, A.; Fritzsche, K.; Schaefert, R. Physical and psychological correlates of high somatic symptom severity in Chinese breast cancer patients. Psycho-Oncol. 2017, 26, 656-663. [CrossRef] [PubMed]

33. Wang, J.; Guo, W.J.; Mo, L.L.; Luo, S.X.; Yu, J.Y.; Dong, Z.Q.; Liu, Y.; Huang, M.J.; Wang, Y.; Chen, L.; et al. Prevalence and strong association of high somatic symptom severity with depression and anxiety in a Chinese inpatient population. Asia-Pacific Psychiatry 2017, 9, e12282. [CrossRef] [PubMed] 